\title{
Food intake and blood cholesterol levels of community-based adults with mood disorders
}

\author{
Karen M Davison ${ }^{1,3+}$ and Bonnie J Kaplan ${ }^{1,2^{*+}}$
}

\begin{abstract}
Background: A growing body of literature links nutrition to mood, especially in epidemiological surveys, but there is little information characterizing food intake in people with diagnosed mood disorders.

Methods: Food intake obtained from 3-day food records was evaluated in 97 adults with mood disorders, whose diagnoses were confirmed in structured interviews. Information from a population nutrition survey, national guidelines for nutritional intakes (Eating Well with Canada's Food Guide) and North American dietary guidelines (Dietary Reference Intakes) was utilized to evaluate the quality of their food intake.

Results: Compared to the regional nutrition survey data and national guidelines, a greater proportion of study participants consumed fewer of the recommended servings of grains $(p<0.001)$ and vegetables and fruits $(p<$ 0.05), and less than the lower boundary of the Adequate Macronutrient Distribution Range (AMDR) for $\alpha$-linolenic acid $(p<0.001)$. The study sample also had greater intakes of high-fat whole grain products $(p<0.01)$, processed meats $(p<0.00001)$, and higher sugar, fat or salty foods $(p<0.00001)$. Of the 1746 total meals and snacks consumed, 39\% were from sources outside the home, suggesting a lack of time devoted to meal preparation. Finally, a subsample of 48 participants agreed to have blood tests: $44 \%$ had mild hypercholesterolemia (> 5.2 and $\leq 6.2 \mathrm{mmol} / \mathrm{L}$ ) and $21 \%$ had hypercholesterolemia (> $6.2 \mathrm{mmol} / \mathrm{L}$ ).
\end{abstract}

Conclusions: Much research has proposed multiple ways in which healthier diets may exert protective effects on mental health. The results of this study suggest that adults with mood disorders could benefit from nutritional interventions to improve diet quality.

\section{Background}

Bipolar disorder and depression are associated with long-lasting disability and significant mortality through suicide, medical illness, and accidental death. As current pharmaceutical treatments have only partial benefit [1], other therapies such as nutritional interventions $[2,3]$ continue to be investigated. Several lines of scientific evidence linking nutrition and mood exist. A substantial number of studies suggest that intake of the essential fatty acids can prevent psychotic disorders [4] or improve mood symptoms [5]. In addition, several nutrition-related concerns have been reported in mood disordered populations [6], such as low income, social isolation, presence of other health problems, drug-

\footnotetext{
* Correspondence: bonnie.kaplan@albertahealthservices.ca

+ Contributed equally

'Department of Community Health Sciences, University of Calgary, Calgary, Alberta, Canada

Full list of author information is available at the end of the article
}

nutrient interactions, and suboptimal eating behaviours $[7,8]$. Finally, recent epidemiologic investigations of dietary intakes suggest the protective effect of better diet quality $[9,10]$. It appears that there is a compelling reason to examine dietary consumption in people with diagnosed mood disorders; however, to date, no studies have actually compared the intakes of this uniquely vulnerable group to nutritional standards.

\section{Methods}

Subjects, settings and procedures

The sampling frame for this study consisted of adult (> 18 years) members of the Mood Disorders Association of British Columbia (MDABC) who resided in BC's lower mainland. Using a computerized random number generation analysis tool, the names of 146 randomly selected MDABC adult members were drawn and sent a letter of invitation to participate in a cross-sectional survey of food intake (73 invited in the summer and 73 in

\section{Ciomed Central}


the fall/winter). When an individual declined participation, the interviewer attempted to complete a nonresponse questionnaire asking about lifestyle habits.

When an individual agreed to participate, the research coordinator explained the study over the phone and trained the respondent to complete a three-day food record (reporting three non-consecutive days, two of which were weekdays and one was a weekend day). Participants were also asked if they would provide a blood sample to measure their cholesterol levels.

At the first appointment, participants read and signed the consent form approved by the University of Calgary's Conjoint Health Research Ethics Board. Then they met with a trained clinical interviewer who administered the Structured Clinical Interview for DSM-IV Axis I Disorders [11], the Global Assessment of Functioning (GAF) Scale (GAF) [12] which measured social, occupational, and psychological functioning (scale of 0 to 100), the Hamilton Depression Scale (Ham-D) [13] and, the Young Mania Rating Scale (YMRS) [14]. Those with conditions associated with psychotic symptoms, dementia, thyroid dysfunction, or neuro-degeneration were excluded. Eligible individuals were subsequently interviewed by a registered dietitian who reviewed the participant's food record, administered a validated food frequency questionnaire [15], and asked selected demographic and health related questions. The procedures for collecting dietary data followed that of the British Columbia Nutrition Survey (BCNS), a study of 1823 British Columbians aged 19-84 years. Detailed reports are available at http://www. health.gov.bc.ca/library/publications/year/2004/ bcnutritionsurvey.

\section{Statistical analysis}

The software program Food Processor SQL [16], which contains the Canadian Nutrient File [17], was used to analyze the food data. The data were compared with the recommended serving ranges of the national guidelines for Canada, Eating Well with Canada's Food Guide (Food Guide) [18], the North American Dietary Reference Intakes [19], and data from the BCNS [15,20]. Components of the Dietary Reference Intakes that were used were 1) Adequate Macronutrient Distribution Ranges (AMDR): range of intakes for a particular energy source and expressed as a percentage of total energy intake that is associated with reduced risk of chronic disease while providing adequate intakes of essential nutrients, and 2) The Estimated Average Requirement (EAR): a nutrient intake value that is estimated to meet the requirements of half the healthy individuals in a group. If an EAR was not available, Adequate Intakes (AI) were used instead. The AI is a recommended daily intake level based on observed or experimentally determined approximations by a group (or groups) of healthy people [19].
Statistical comparisons between the sample and BCNS as well as analyses within the study group of sociodemographic variables, type of mood disorder and dietary attributes were carried out using Student's t-tests, Mann-Whitney two-sample statistics, binomial tests of two proportions, Pearson's or Spearman's rho correlations, and ANOVA where appropriate.

\section{Results \\ Sample}

The overall response rate was $75 \%$ (number of participants/number of possibly eligible participants based on the initial phone screening). Of those who declined participation, 44\% (11/25) answered the non-response survey: no differences in lifestyle variables (e.g., smoking) were found when compared to the respondents. Sociodemographic characteristics of the sample with comparisons to the BCNS are outlined in Table 1. Slightly more than half of the sample had bipolar disorder (i.e., 59.8\% had bipolar disorder and $40.2 \%$ had depressive disorder) with relatively high GAF scores $(62.7 \pm 14.7)$ suggesting most were only mildly to moderately impaired. The Ham-D scores indicated that 14 (14.4\%) were severely depressed, 14 (14.4\%) were experiencing moderate depressive symptoms, 44 (45.4\%) were mildly depressed, and the remainder were asymptomatic. Based on YMRS scores, 2.6\% (all females) were experiencing symptoms of mania. The sample tended to be overweight or obese $(67 \%$ had a $\mathrm{BMI} \geq 25$ ). The main psychiatric medications taken by

Table 1 Characteristics of the study $(n=97)$ and BCNS participants $(n=1823)$

\begin{tabular}{lcc}
\hline Characteristic & $\begin{array}{c}\text { Study } \\
\text { Sample } \\
\text { N (\% of } \\
\text { total) }\end{array}$ & $\begin{array}{c}\text { BCNS } \\
\text { N (\% of } \\
\text { total) }\end{array}$ \\
\hline Gender: & $28(28.9 \%)^{* *}$ & $868(47.6 \%)$ \\
\hline Male & $69(71.1 \%)^{* *}$ & $955(52.4 \%)$ \\
\hline Female & $21(21.6 \%)^{* *}$ & $737(40.8 \%)$ \\
\hline Education level': & $46(47.4 \%)$ & $810(44.8 \%)$ \\
\hline Completed high school or less & $30(30.9 \%)^{* * *}$ & $261(14.4 \%)$ \\
\hline Technical school/some university & $37(38.1 \%)^{* * *}$ & $1178(65.2 \%)$ \\
\hline University degree & $27(27.8 \%)$ & $358(19.8 \%)$ \\
\hline Marital status ${ }^{2}:$ & $33(34.0 \%)^{* * * *} 273(15.1 \%)$ \\
\hline Married or common law & $20(20.6 \%)$ & $301(16.5 \%)$ \\
\hline Divorced/separated/never married/ & & \\
widowed & & \\
\hline Single & & \\
\hline Smokers & & \\
\hline${ }^{* *} p<0.001$ \\
***p $<0.0001$
\end{tabular}


the sample included various antidepressants $(72.9 \%)$ and mood stabilizers (52.9\%).

\section{Comparison of sample to the regional nutrition survey (BCNS)}

Analysis of nutrient intakes and demographic attributes indicated significantly higher intakes of protein $[\mathrm{F}(3,93)$ $=4.40, p<0.05]$ and fibre $[\mathrm{F}(3,93)=3.07, p<0.05]$ based on education, and significantly lower intakes for energy $(t=-2.19, \mathrm{SE}=195.03,95 \% \mathrm{CI}=-815.01$ to $-40.63, p<0.05)$ and fibre $(\mathrm{t}=-2.40, \mathrm{SE}=2.87,95 \% \mathrm{CI}=$ -12.60 to $-1.19, p<0.05)$ for those who were considered single (i.e., widowed, divorced, separated, or never married). All nutrients were also compared based on age (18 to 34,35 to 49 , and $50+$ years for food group analysis and 19 to 30,31 to 50 and 51 to 70 years for nutrient analysis to be consistent with the standards used). None of the study participants exceeded the age of 70 ; therefore the subsample of 1320 participants aged 19-70 from the full 1823 BCNS sample was used as the comparison group. Only $19 \%$ of participants indicated they were following a therapeutic diet; this subsample had significantly lower carbohydrate intake ( $255 \mathrm{~g} \pm 103$ vs $341 \mathrm{~g} \pm 145$; $\mathrm{t}=2.40$, $p<0.05,95 \%$ CI 14.78 to 156.07$)$.

\section{Comparisons using national guidelines, Eating Well with Canada's Food Guide}

Eighty-nine (92\%) participants claimed to have heard of Canada's Food Guide, but less than one-third $(\mathrm{n}=30$; $31 \%$ ) actually used it; there were no significant differences in major nutrient intakes between those who reported that they did and did not use the Food Guide. When compared to the 2007 Eating Well with Canada's Food Guide [18] (Table 2), intakes of the study sample within the recommended serving ranges of each of the food groups were significantly lower than the BCNS ( $p$ 's $<0.05$ to 0.0001 ) with the exception of milk and milk alternatives. Analyses according to age groupings and gender indicated significantly more males between the ages of 18 to 34 and 35 to 49 years ate less than the minimum recommendations for fruits and vegetables $(p<$ $0.05)$ and grains $(p<0.001)$ compared to the BCNS. Significantly fewer females between the ages of 35 to 49 years consumed the recommended 5 to 12 servings of fruits and vegetables per day $(p<0.05)$ compared to the BCNS. There also tended to be more males across all age groups consuming less than $100 \mathrm{~g}$ of meat and alternatives per day (range of $p<0.05$ to $p<0.0001$ ). In summary, only $6.2 \%$ of the sample consumed the minimum recommended level of servings across all food groups. In order to meet the Food Guide standard, at least $45 \%$ of the sample needed to add 2-3 more daily servings of vegetables and fruit; about $15 \%$ required 2 extra grain servings daily ( $30 \%$ need 1 extra grain serving); and about half would need to add 1 serving/day of milk and alternatives.

\section{Comparisons using the North American guidelines: Dietary Reference Intakes}

Median energy intakes (kilocalories) of the study sample were $2520\left(25^{\text {th }}\right.$ percentile $1920 ; 75^{\text {th }}$ percentile 3050$)$; there was slight under-reporting. The study sample had significantly higher total fat intakes ( $45 \%$ vs $19 \%$ of the BCNS, $p<0.0001)$ and lower $\alpha$-linolenic acid intakes (91\% vs $23 \%$ of BCNS, $p<0.001$ ) (Table 2). Median $\alpha$-linolenic intakes did not meet the AI of 1.6. grams/day for males and $1.1 \mathrm{~g} /$ day for females and intakes were consistently lower than the BCNS (Figure 1). About 10\% of the sample were below the EAR $(0.66 \mathrm{~g} / \mathrm{kg} /$ day $)$ for protein, which is considered the minimum continuing intake of dietary protein required for body nitrogen equilibrium [19].

Age and gender analysis revealed that a significantly lower proportion of males (12\%) between 31 to 50 years had fat intakes that were 30 to $35 \%$ of total calories ( $41 \%$ for BCNS). In addition, 2\% (all females 51 to 70 years) were consuming less than the EAR for carbohydrates. Median carbohydrate intakes (grams) of females 19 to 30 years ( 488 vs $257, p<0.05$ ) and 31 to 50 years ( 326 vs 219 , $p<0.05)$ were significantly higher than the BCNS. Only females 19 to 30 years met the AI for fibre. Fibre intakes may be underestimated by about $5 \mathrm{~g} /$ day, as inulin and fructo-oligosaccharides were not included [19].

\section{Description of food intakes by food subgroups and source}

Compared to the BCNS, the study sample had significantly greater intakes of less healthy foods such as high-fat whole grain products (e.g., granola cereals), processed meats, and higher sugar, fat or salt foods (range of $p$ 's $<0.01$ to 0.00001 ) (Table 3). When comparing those who were and were not taking psychiatric medications, there were no differences found for food group, fat and sugar intakes. Participants were also asked about the frequency of meal and snack food intake from sources outside the home based on the three day food record. Of the 1746 total meals and snacks consumed, 11\% were from fast food sources, $10 \%$ from vending machines or snack bars, 18\% from restaurants, take-out or deli. When asked who prepared most of the foods they ate that day, males reported fewer food preparation days $(\mathrm{n}=25 / 84 ; 29.8 \%)$ than females $(199 / 207$; 96.1\%) $(p<0.0001)$.

\section{Blood cholesterol levels}

Of the 48 participants who agreed to blood tests, $44 \%$ had mild hypercholesterolemia (> 5.2 and $\leq 6.2 \mathrm{mmol} /$ $\mathrm{L})$ and $21 \%$ had hypercholesterolemia (> $6.2 \mathrm{mmol} / \mathrm{L})$. The prevalence of total cholesterol levels exceeding 5.2 $\mathrm{mmol} / \mathrm{L}$ in the Canadian population is $41 \%$ [21]. Blood 
Table 2 Food intakes of adults with mood disorders according to Eating Well with Canada's Food Guide (CFG) servings and DRIs and compared to the BCNS

\begin{tabular}{|c|c|c|}
\hline & Study $(n=97)$ & $\mathrm{BCNS}(\mathrm{n}=1320)^{1}$ \\
\hline \multicolumn{3}{|l|}{ 1. Comparisons with CFG servings: } \\
\hline \multicolumn{3}{|l|}{ a. Grains (\%) } \\
\hline$<5$ svgs/day & $59^{* *}$ & 41 \\
\hline 5-12 svgs/day & $37^{* *}$ & 57 \\
\hline$>12$ svgs/day & 5 & 2 \\
\hline \multicolumn{3}{|l|}{ b. Vegetables and fruit (\%) } \\
\hline$<5$ svgs/day & $75^{*}$ & 65 \\
\hline 5-10 svgs/day & $23^{*}$ & 32 \\
\hline$>10$ svgs/day & 2 & 3 \\
\hline \multicolumn{3}{|l|}{ c. Meat and alternatives (\%) } \\
\hline$<100 \mathrm{~g} /$ day & $40^{*}$ & 26 \\
\hline $100-300 \mathrm{~g} /$ day & $37^{* * *}$ & 66 \\
\hline$>300 \mathrm{~g} /$ day & $22^{* * *}$ & 8 \\
\hline \multicolumn{3}{|l|}{ d. Milk and milk alternatives (\%) } \\
\hline$<2$ svgs/day & $51 * * *$ & 77 \\
\hline $2-4$ svgs/day & $39 * * *$ & 20 \\
\hline$>4$ svgs/day & $10^{* * *}$ & 3 \\
\hline \multicolumn{3}{|l|}{ 2. Comparisons with DRIs: } \\
\hline \multicolumn{3}{|l|}{ a. Carbohydrates } \\
\hline i. Grams - median $\left(25^{\text {th }} ; 75^{\text {th }} \%\right.$ ile $)$ & $305(215 ; 405)$ & \\
\hline \multicolumn{3}{|l|}{ ii. Intake (\%) by $\mathrm{AMDR}^{2}$} \\
\hline$<45$ & 27 & 22 \\
\hline$\geq 45$ to $<65$ & $65^{*}$ & 76 \\
\hline$\geq 65$ & 8 & 2 \\
\hline \multicolumn{3}{|l|}{ b. Fat } \\
\hline i. Grams - median $\left(25^{\text {th }} ; 75^{\text {th }} \%\right.$ ile $)$ & $90(64 ; 123)$ & \\
\hline \multicolumn{3}{|l|}{ ii. Intake (\%) by AMDR ${ }^{2}$} \\
\hline$<20$ & 3 & 1 \\
\hline$\geq 20$ to $<35$ & $46^{* *}$ & 74 \\
\hline$\geq 35$ to $<40$ & $45^{* * *}$ & 19 \\
\hline$\geq 40$ & 5 & 6 \\
\hline \multicolumn{3}{|l|}{ c. Protein } \\
\hline i. Grams of intake per kilogram body weight - median $\left(25^{\text {th }} ; 75^{\text {th }} \%\right.$ ile) & $1.16(0.87 ; 1.53)$ & \\
\hline \multicolumn{3}{|l|}{ ii. Intake (\%) by AMDR ${ }^{2}$} \\
\hline$<10$ & 4 & 2 \\
\hline$\geq 10$ to $<30$ & 94 & 98 \\
\hline$\geq 30$ & 2 & 0 \\
\hline \multicolumn{3}{|l|}{ d. Saturated fat $^{3}$} \\
\hline i. Grams - median $\left(25^{\text {th }} ; 75^{\text {th }} \%\right.$ ile $)$ & $28(18 ; 38)$ & \\
\hline \multicolumn{3}{|l|}{ ii. \% of total energy intake } \\
\hline$<5 \%$ & 5 & 2 \\
\hline$\geq 5$ to $<10$ & $38^{*}$ & 51 \\
\hline$\geq 10$ to $<20$ & $56^{*}$ & 47 \\
\hline$\geq 20$ & 1 & 0 \\
\hline \multicolumn{3}{|l|}{ e. Linoleic acid } \\
\hline i. Grams - median $\left(25^{\text {th }} ; 75^{\text {th }} \%\right.$ ile $)$ & $2.6(1.6 ; 3.7)$ & \\
\hline
\end{tabular}


Table 2 Food intakes of adults with mood disorders according to Eating Well with Canada's Food Guide (CFG) servings and DRIs and compared to the BCNS (Continued)

\begin{tabular}{|c|c|c|}
\hline ii. Intake (\%) by $\mathrm{AMDR}^{2}$ & & \\
\hline$<5$ & $96^{* *}$ & 76 \\
\hline$\geq 5$ to $<10$ & $3^{* *}$ & 24 \\
\hline$\geq 10$ & 1 & $<1$ \\
\hline \multicolumn{3}{|l|}{ f. $\alpha$-Linolenic acid } \\
\hline i. Grams - median $\left(25^{\text {th }} ; 75^{\text {th }} \%\right.$ ile $)$ & $0.3(0.1 ; 0.4)$ & \\
\hline \multicolumn{3}{|l|}{ ii. Intake (\%) by AMDR $^{2}$} \\
\hline$<0.6$ & $91^{* *}$ & 23 \\
\hline$\geq 0.6$ to $<1.2$ & $7^{* *}$ & 70 \\
\hline$\geq 1.2$ & $1^{*}$ & 7 \\
\hline
\end{tabular}

*Significant differences between study and BCNS samples at $p<0.05$

**Significant differences between study and BCNS samples at $p<0.001$

***Significant differences between study and BCNS samples at $p<0.0001$

${ }^{1} 1320$ participants from BCNS that were between the ages of 19 to 70 years

${ }^{2}$ Adequate Macronutrient Distribution Range (AMDR) of Dietary Reference Intakes

${ }^{3} \mathrm{No}$ AMDR is set for saturated fats

svgs servings; $g$ grams

Note: all statistical results in this table are based on binomial tests of two proportions. The shaded areas represent the recommended levels according to Eating Well with Canada's Food Guide or the Acceptable Macronutrient Distribution Ranges (AMDR) of the Dietary Reference Intakes

cholesterol levels did not differ based on psychiatric medication use, type of mood disorder or BMI status.

\section{Discussion}

The primary aim of this study was to examine the quality of dietary intakes in adults with diagnosed mood disorders using comparisons to national and international nutrition standards as well as regional nutrition survey data. Our results were consistent with others [22] that have revealed many indications of poor diet quality in this population.

The low intakes of grains, vegetables and fruit, and meat and alternatives coupled with the high intakes of foods with excess sugar and fat may compromise mental

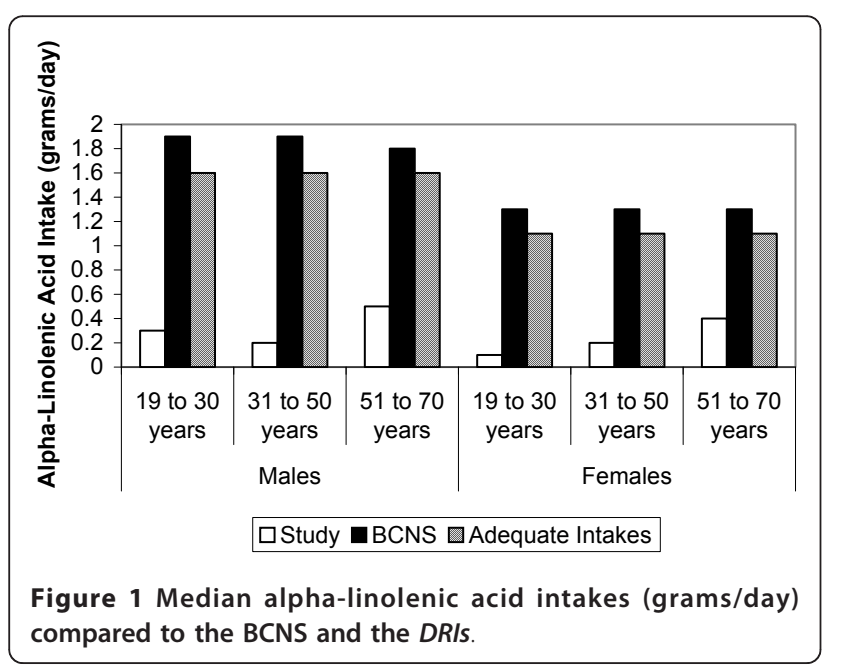

health status [23,24]. Comparison of carbohydrate (main sources are plants) intakes with the AMDRs showed that more than a quarter of the sample $(28 \%)$ were below the lower boundary; two participants consumed less than the EAR which is based on the amount needed to produce enough glucose for essential brain activities. About $10 \%$ of the sample had intakes of protein less than the EAR, suggesting that important neurotransmitter precursors such as tryptophan may be lacking in the diets of some individuals. Nutrients commonly associated with good mental health include polyunsaturated fatty acids (particularly the omega 3 types), minerals such as zinc, magnesium, and iron, a range of B vitamins particularly folate, and antioxidant vitamins such as $C$ and $E$ most of which are found in diets rich in dark green leafy and orange-coloured vegetables and whole grains. Evidence is accumulating that the combination of polyunsaturated fats, minerals and vitamins may help to relieve the symptoms of some mental illnesses and improve the effectiveness of medication for some conditions $[25,26]$.

Closer examination of the intakes of the major nutrients suggests many implications for negative mental health effects in this population. The high total and saturated fat diets found in this sample have been associated with reduced hippocampal levels of neurotrophic factor, a crucial modulator of synaptic plasticity [27], which can induce cognitive dysfunction [28]. Low intakes of omega3 fatty acids impair astrocyte-mediated vascular coupling that contributes to reduced gray matter volume in the prefrontal cortex [29] and research has suggested that lipid profiles comprising a low docosahexaenoic acid 
Table 3 Comparison of portions consumed to the BCNS

\begin{tabular}{|c|c|c|}
\hline Food group & $\begin{array}{c}\text { Study } \\
\% \text { of total portions }{ }^{\mathrm{a}} \\
\text { (\# of total portions) }\end{array}$ & $\begin{array}{c}\text { BCNS } \\
\% \text { of total portions } \\
\text { (\# of total portions) }\end{array}$ \\
\hline 1. Grains (total) & $100(438)$ & 100 (11346) \\
\hline Whole $e^{* * *}$ & $10.3(45)$ & $16.6(1889)$ \\
\hline Non-whole - high fat**** & $66.0(289)$ & $18.9(2143)$ \\
\hline 2. Fruit (total) & $100(152)$ & $100(3954)$ \\
\hline Fruit (deep yellow/orange) & $3.9(6)$ & $4.9(195)$ \\
\hline Fruit (other types) & $39.5(60)$ & $57.4(2271)$ \\
\hline Fruit juice or nectars ${ }^{* * * *}$ & $56.6(86)$ & $37.6(1488)$ \\
\hline 3. Vegetables (total) & $100(346)$ & $100(5397)$ \\
\hline Vegetables (dark green)* $^{*}$ & $4.9(17)$ & $9.4(508)$ \\
\hline Vegetables (deep yellow/orange)* & $4.6(16)$ & $9.3(503)$ \\
\hline 4. Milk and milk alternatives (total) & $100(607)$ & $100(4104)$ \\
\hline Milk and fortified plant beverages - high fat ${ }^{* * * *}$ & $9.1(55)$ & $29.4(1208)$ \\
\hline Milk products (other) - high fat**** & $7.9(48)$ & $25.8(1060)$ \\
\hline 5. Meat ${ }^{\mathrm{b}}$ (total) & $100(27227)$ & 100 (252139) \\
\hline Meat (beef, poultry, etc.) - high fat ${ }^{* * * *}$ & $19.8(5404)$ & 37.6 (94759) \\
\hline Fish and shellfish - high fat ${ }^{* * * *}$ & $6.5(1771)$ & $5.7(14463)$ \\
\hline Meat (processed) - high fat ${ }^{* * * *}$ & $13.9(3795)$ & $10.3(25942)$ \\
\hline 6. Meat alternate ${ }^{\mathrm{b}}$ (total) & $100(6305)$ & $100(67781)$ \\
\hline Legumes - high fat*** & $24.3(1532)$ & $26.6(18033)$ \\
\hline Nuts and seeds**** & $5.9(371)$ & $7.6(5165)$ \\
\hline Eggs* & $53.8(3393)$ & $52.3(35482)$ \\
\hline 7. Other foods ${ }^{\complement}$ (total) & $100(161657)$ & $100(3545506)$ \\
\hline Mostly fat, sugar or sodium foods $s^{* * *}$ & $75.7(122421)$ & 3.9 (139494) \\
\hline Beverages - high calorie ${ }^{d * * * *}$ & $0.5(913)$ & $5.4(189756)$ \\
\hline
\end{tabular}

*Significant differences between study and BCNS samples at $p<0.05$

**Significant differences between study and BCNS samples at $p<0.001$

***Significant differences between study and BCNS samples at $p<0.0001$

*** Significant differences between study and BCNS samples at $p<0.00001$

${ }^{a}$ Column totals for each subgroup will not add to $100 \%$ because only selected food variables are presented

${ }^{\mathrm{b}}$ Expressed as number of 50-gram equivalents consumed: 0-25 grams $=0$ serving; 2$) 25-49$ grams = 1/2 serving; 3) 50-99 grams = 1 serving; 4) 100-300 grams = 2-3 servings, and 5) 301-600 grams $=4-6$ servings

${ }^{c}$ Expressed as grams consumed and not portions

${ }^{d}$ Excludes water, coffee, tea, low-calorie soft drinks

percentage and omega-3 proportions predicted risk of suicidal behaviour among depressed patients over a 2year period [30]. The high proportion of participants with hypercholesterolemia (further suggesting excess fat intakes) also has mental health implications. Studies of people with elevated blood cholesterol levels have shown that global severity of psychological symptoms is worsened with high fat, low-complex carbohydrate diets [31]. Lipid-lowering medications are standard treatment for hypercholesterolemia, however, these drugs can form complexes with lipoproteins, alter the medication's pharmacokinetics and lead to deterioration of mental symptoms [32]; dietary interventions do not present these risks.
The limitations of this study include biases related to recall, sample selection (i.e., participants were drawn mainly from an urban sample of a non-profit network), and misclassification (i.e., with AMDRs). Males were under-represented, which may limit generalizability. The samples compared (i.e., study versus BCNS) did differ on some variables (e.g., income levels) that can affect food choice, however both samples were drawn based on random selection. Finally, this cross-sectional study cannot determine the temporal sequence of disease and nutrient intake.

One of the study's strengths is that it provided quantified comparisons of nutrient intakes to the general local population, which have never been reported previously 
for mood disorders. This investigation also determined the prevalence of various nutrition-related factors in a mood disorder sample and is therefore useful for future hypothesis generation and planning of health services.

Dietary intakes in this sample of adults with mood disorders tended to consist of a high proportion of foods associated with neuronal impairment (e.g., high fat, high sugar) and limited dietary components associated with neuro-protection (e.g., fibre, antioxidants). People with mood disorders have a greater frequency of poor diet for several reasons such as the occurrence of depressive episodes that exacerbate a sedentary lifestyle associated with lack of exercise, weight gain, and cardiovascular disease and diabetes risk, or manic episodes that may be associated with treatment non-adherence. Other factors such as food insecurity, co-existing medical problems, or substance use may also explain the association between mood disorders and poor nutrition status. The negative impact of poor dietary intake in individuals with mood disorders may be exacerbated by the fact that health providers are unlikely to discuss diet habits with them, according to patient report [33].

\section{Conclusions}

Based on these findings, it is evident that individuals with mood disorders would benefit from diet-specific interventions that go beyond familiarization with Canada's Food Guide to optimize health. However, there is lack of research indicating what types of nutritionrelated programs would be most effective for individuals with serious mental disorders. Future directions in the area of diet in mental disorders should focus on interventions that include appropriate modification of the major nutrients and that increase foods offering neuroprotection and the investigation of their outcomes.

\section{Abbreviations \\ AMDR: Adequate macronutrient distribution ranges; EARs: Estimated average requirements; BCNS: British Columbia Nutrition Survey; Al: Adequate Intake.}

\section{Acknowledgements \\ The authors thank their funding source, The Danone Research Institute. The second author also thanks the Alberta Children's Hospital Research Institute for ongoing support. We also acknowledge the assistance of the Mood Disorders Association of British Columbia (including Ed Rogers, Vicki Rogers, Julia Zohab, Johannes Presley and Rennie Hoffman) for providing support staff, office space and assistance with recruitment. Gratitude is also extended to the nutrition and clinical interviewers (Sue Maxwell, Erin Putterman, Maggie Hanson, Lindsay Thomas and Janine Moseley), as well as to Dr. Ronald A. Remick and Wendy Heathcote for their assistance in organizing the participant blood collection and analysis.}

\section{Author details}

'Department of Community Health Sciences, University of Calgary, Calgary, Alberta, Canada. ${ }^{2}$ Department of Paediatrics, University of Calgary, and the Alberta Children's Hospital Research Institute, Calgary, Alberta, Canada. ${ }^{3}$ IMPART Program, British Columbia Centre of Excellence for Women's Health, Vancouver, British Columbia, Canada.

\section{Authors' contributions}

KMD carried out this study as part of her requirement for a PhD in the Faculty of Medicine, University of Calgary, under the supervision of BJK, and is currently a postdoctoral research fellow with the IMPART Program at the British Columbia Centre of Excellence for Women's Health. BJK is a Professor in the Faculty of Medicine at the University of Calgary who studies nutrition in relation to mental development and function.

\section{Competing interests}

The authors declare that they have no competing interests.

Received: 18 August 2011 Accepted: 14 February 2012

Published: 14 February 2012

\section{References}

1. Muench J, Hamer AM: Adverse effects of antipsychotic medications. Am Fam Physician 2010, 81.

2. Kennedy DO, Veasey R, Watson A, Dodd F, Jones E, Maggini S, Haskell CF: Effects of high-dose B vitamin complex with vitamin $C$ and minerals on subjective mood and performance in healthy males. Psychopharmacology (Berl) 2010, 211.

3. Gately D, Kaplan BJ: Database analysis of adults with bipolar disorder consuming a micronutrient formula. Clin Med Insights: Psychiatry 2009, 4:3-16.

4. Amminger GP, Schafer MR, Papageorgiou K, Klier CM, Cotton SM, Harrigan SM, Mackinnon A, McGorry PD, Berger GE: Long-chain omega-3 fatty acids for indicated prevention of psychotic disorders: a randomized, placebo-controlled trial. Arch Gen Psychiatry 2010, 67.

5. Lin P, Su K: A meta-analytic review of double-blind, placebo-controlled trials of antidepressant efficacy of omega-3 fatty acids. J Clin Psychiatry 2007, 68.

6. Simon GE, Unutzer J: Health care utilization and costs among patients treated for bipolar disorder in an insured population. Psychiatr Serv 1999, 50.

7. Kaplan BJ, Shannon S: Nutritional aspects of child and adolescent psychopharmacology. Pediatr Ann 2007, 36.

8. Osborn DP: The poor physical health of people with mental illness. West J Med 2001, 175.

9. Akbaraly TN, Brunner EJ, Ferrie JE, Marmot MG, Kivimaki M, SinghManoux A: Dietary pattern and depressive symptoms in middle age. $\mathrm{Br} J$ Psychiatry 2009, 195.

10. Jacka FN, Pasco JA, Mykletun A, Williams $L$, Hodge AM, O'Reilly SL, Nicholson GC, Kotowicz MA, Berk M: Association of Western and traditional diets with depression and anxiety in women. Am J Psychiatry 2010, 167.

11. First MB, Spitzer RL, Gibbon M, Williams JBW: Structured Clinical Interview for DSM-IV-TR Axis I Disorders, Research Edition: Non-patient Edition (SCID-I/NP) ed New York: Biometrics Research, New York State Psychiatric Institute; 2001.

12. Endicott J, Spitzer RL, Fleiss JL, Cohen J: The global assessment scale: a procedure for measuring overall severity of psychiatric disturbance. Arch Gen Psychiatry 1976, 33:766-771.

13. Hamilton M: A rating scale for depression. J Neurol Neurosurg Psychiatry 1960, 23:62.

14. Young RC, Biggs JT, Ziegler VE, Meyer DA: A rating scale for mania: reliability, validity and sensitivity. Br J Psychiatry 1978, 133:429-435.

15. Forster-Coull L, Barr SI, Levy-Milne R: British Columbia Nutrition Survey: Report on Food Group Use Victoria: British Columbia Ministry of Health Services; 2004.

16. ESHA Research: Food Processor SQL Salem: ESHA Research; 2006.

17. Nutrition Research Division: Health Canada: Canadian Nutrient File Ottawa: Health Canada; 2007.

18. Health Canada: Eating Well with Canada's Food Guide: A Resource for Educators and Communicators Ottawa: Health Canada; 2007.

19. Subcommittee on Interpretation and Uses of Dietary Reference Intakes and the Standing Committee on the Scientific Evaluation of Dietary Reference Intakes, Food and Nutrition Board, Institute of Medicine: Dietary Reference Intakes: Applications in Dietary Assessment Washington: Institute of Medicine; 2000.

20. Forster-Coull L, Barr SI, Levy-Milne R: British Columbia Nutrition Survey: Report on Energy and Nutrient Intakes Victoria: British Columbia Ministry of Health Services; 2004 
21. Statistics Canada: Heart health and cholesterol levels of Canadians, 2007 to 2009 Ottawa: Statistics Canada; 2010.

22. Kilbourne AM, Rofey DL, MCDarthy JF, Post EP, Welsh D, Blow FC: Nutrition and exercise behaviour among patients with bipolar disorder. Bipolar Disord 2007, 9:443-452.

23. Hasegawa Y, Suehiro A, Higasa S, Namba M, Kakishita E: Enhancing effect of advanced glycation end products on serotonin-induced platelet aggregation in patients with diabetes mellitus. Thromb Res 2002, 107.

24. Emanuele $E$, D'Angelo A, Tomaino C, Binetti G, Ghidoni R, Politi P, Bernardi L, Maletta R, Bruni AC, Geroldi D: Circulating levels of soluble receptor for advanced glycation end products in Alzheimer disease and vascular dementia. Arch Neurol 2005, 62.

25. Davison KM, Kaplan BJ: Nutrient intakes are correlated with overall psychiatric functioning in adults with mood disorders. Can J Psychiatry

26. Kaplan BJ, Crawford SG, Field CJ, Simpson JSA: Vitamins, Minerals, and Mood. Psychol Bull 2007, 133:747-760.

27. Molteni R, Wu A, Vaynman S, Ying Z, Barnard RJ, Gomez-Pinilla F: Exercise reverses the harmful effects of consumption of a high-fat diet on synaptic and behavioral plasticity associated to the action of brainderived neurotrophic factor. Neuroscience 2004, 123.

28. Park HR, Park M, Choi J, Park KY, Chung HY, Lee J: A high-fat diet impairs neurogenesis: involvement of lipid peroxidation and brain-derived neurotrophic factor. Neurosci Lett 2010, 482:235-239.

29. McNamara RK: DHA deficiency and prefrontal cortex neuropathology in recurrent affective disorders. I Nutr 2010, 140.

30. Sublette ME, Hibbeln JR, Galfalvy H, Oquendo MA, Mann JJ: Omega-3 polyunsaturated essential fatty acid status as a predictor of future suicide risk. Am J Psychiatry 2006, 163.

31. Weidner G, Connor SL, Gerhard GT, Duell PB, Connor WE: The effects of dietary cholesterol-lowering on psychological symptoms: a randomised controlled study. Psychol Health Med 2009, 14.

32. Procyshyn RM, Chau A, Tse G: Clozapine's effects on body weight and resting metabolic rate: a case series. Schizophr Res 2004, 66.

33. Abayomi J, Hackett A: Assessment of malnutrition in mental health clients: nurses' judgement vs. a nutrition risk tool. J Adv Nurs 2004, 45.

Pre-publication history

The pre-publication history for this paper can be accessed here: http://www.biomedcentral.com/1471-244X/12/10/prepub

doi:10.1186/1471-244X-12-10

Cite this article as: Davison and Kaplan: Food intake and blood cholesterol levels of community-based adults with mood disorders. BMC Psychiatry 2012 12:10.

\section{Submit your next manuscript to BioMed Central and take full advantage of:}

- Convenient online submission

- Thorough peer review

- No space constraints or color figure charges

- Immediate publication on acceptance

- Inclusion in PubMed, CAS, Scopus and Google Scholar

- Research which is freely available for redistribution 